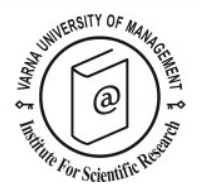

\title{
Segmenting protected area visitors by activities: A case study in Paklenica National Park, Croatia
}

\author{
Demir Barić $^{1 *}$, Petra Anić ${ }^{2}$ and Ana Macías Bedoya ${ }^{1}$ \\ Received: 18/09/2015 Accepted: 24/01/2016
}

\footnotetext{
1 Departamento Historia, Geografía y Filosofía. Grupo de Investigación en Gestión Integrada de Áreas Litorales, Facultad de Ciencias del Mar y Ambientales Universidad de Cádiz, Polígono Río San Pedro, s/n, 11510, Puerto Real, Cadiz, Spain

${ }^{2}$ Department of Psychology, Faculty of Humanities and Social Sciences, Sveučilišna avenija 4, 51000 Rijeka, Croatia

* Corresponding author, phone: +34 627275673; email: demir.baric@alum.uca.es
}

\begin{abstract}
To date, a variety of market segmentation approaches have been employed to identify homogenous visitor segments in wilderness and protected area settings. This study focuses on activity-based segmentation of specific subgroups of visitors, specifically visitors of Paklenica National Park, Croatia. Data were randomly collected from visitors by means of self-administered questionnaires using a face-to-face approach $(n=352)$. Hierarchical and non-hierarchical cluster analysis enabled the identification of two distinct and managerially relevant segments: Activists and Passivists. The segments were characterised by the perceived importance of desired benefits, travel behaviour, environmental commitment and socio-demographic characteristics. The study findings revealed significant segment differences in terms of the perceived importance of desired benefits, travel behaviour and environmental commitment. Yet, for each segment, inter-correlations between the desired benefit dimensions were examined. Here, the results indicated that each segment was more likely to perceive desired benefits through the wider prism of their positive mutual relationships than by considering them to be a self-determining unit. Socio-demographic descriptors exhibited a weak role in segment characterisation. The study findings might directly assist Park managers to develop more effective visitor management strategies and to enhance marketing strategies in general. Specific practical implications of the study findings are also discussed.
\end{abstract}

(C) 2016 Varna University of Management. All rights reserved

Keywords: visitors, protected areas, national park, nature-based tourism, activity-based segmentation.

Citation: Barić, D., P. Anić and M. Bedoya (2016) Segmenting protected area visitors by activities: A case study in Paklenica National Park, Croatia. European Journal of Tourism Research 13, pp. 103-121

\section{Introduction}

Tourism occurring in a natural setting has been labelled variously, such as "nature tourism", "nature-based tourism" or "natural areas tourism". Regardless of the label employed, nature-based tourism is commonly perceived 
as an umbrella term that encompasses different tourism subsets (i.e., ecotourism, nature tourism, and adventure tourism) for which the natural outdoor environment, in its wild and undeveloped form, stands as a key setting for tourists' recreational activities (Buckley, 2008; Fennell, 2007; Hall and Boyd, 2005; Newsome, Moore and Dowling, 2002). Because this paper is not aimed at re-opening further definitional debates, the present authors will use the term nature-based tourism and provide a sample of basic characteristics of mentioned subsets to set up the theoretical grounds for the current study.

Ecotourism has often been interpreted interchangeably with nature-based tourism; however, recent reports clearly acknowledge ecotourism as a specific component (Fennell 2007; Newsome, Moore and Dowling, 2002; Weaver 2001a). Nonetheless, the scope and meaning of ecotourism continue to be debated. The majority of provided definitions agree that ecotourism refers to an environmentally responsible type of travel to relatively undisturbed natural and cultural areas that $(i)$ fosters environmental education, learning and appreciation, (ii) contributes to the conservation of the natural environment and its optimal use and (iii) encourages the socio-economic prosperity of the host community (Diamantis, 1999; Fennell, 2007; Weaver, Lawton and Faulkner, 1999; Weaver, 2001b; Wight, 1993). Thus, although ecotourism is in essence nature based, it advocates a more responsible means of travel, emphasising environmental education and socio-ecologically sustainable use of the natural and cultural environment upon which it inherently depends (Orams, 1995; Weaver, 2001a).

Nature tourism refers to the observation or contemplation of flora, fauna or landscape scenery. In other words, it primarily focuses on nature itself, i.e., its attractiveness and individual experiences, without considering socio-cultural aspects or management issues. It is used more by analysts than practitioners (Buckley, 2008). Adventure tourism is perceived as a type of travel to remote or exotic places to receive active exposure to unknown experiences that often involve a certain level of risk and personal challenge. Reassembling
Walle (1997), Weber (2001) noted that the definition of adventure tourism need not be viewed entirely through the conceptual prism of "risk theory" because the meaning of adventure itself is more a question of the subjective perception of an individual. Adventure tourism is considered a part of nature-based tourism only when the natural environment is used as a setting for participation in outdoor recreational activities (Swarbrook, Beard, Leckie and Pomfret, 2003). Although the key motive of adventure travel is, at its core, the activity (Sung, Morrison and O'Leary, 1997), if managed in a socio-ecological sustainable fashion, such travel might overlap with the ecotourism that frequently occurs in mountain and alpine regions (Williams, Singh and Schlüter, 2001).

The significance of nature-based tourism is widely supported in the tourism literature; is often considered the fastest growing segment within the tourism industry, with an increase of between $10 \%$ and $30 \%$ per year (Balmford, et al., 2009; Marques, Reis and Menezes, 2010; Mehmetoglu 2007; Newsome, Moore and Dowling, 2002; Nyaupane, Morais and Graefe, 2004; Pickering and Weaver, 2003). According to the Centre for Responsible Travel (2015), $10-20 \%$ of all global international travels are, directly or indirectly, associated to enjoyment and interaction with nature. On an European level, when considering a return to the same place for a holiday, slightly less than half $(46 \%)$ of European citizens named nature attractiveness (e.g., landscape) as the key consideration (Eurobarometer, 2014). However, some authors (e.g., Balmford et al., 2009; Page and Dowling, 2002) noted that, although valuable, provided estimations and figures should be interpreted with caution because many of them, in fact, are approximations rarely supported by consistent statistics targeted to measure specific features of nature-based tourism.

Nature-based tourism attractions might vary; however, protected areas stand as their largest and most important component (Balmford et al., 2009). Among these, national parks enjoy a special reputation as globally recognised labels for experiencing high-quality pristine nature, environmental education and engagement in a 
variety of outdoor recreational activities often supported by well-designed infrastructure (Mason, 2005; Nyaupane, Morais and Graefe, 2004). Consequently, in addition to the conservation of biodiversity as an overarching aim, for many protected areas, particularly national parks, outdoor recreation management stands as a key priority (Arnberger, et al., 2012; Cessford and Muhar, 2003; Pigram and Jenkin, 2006; Ryan and Sterling, 2001). Outdoor recreation refers to interaction between an activity and an outdoor natural environment, aimed to provide the individual opportunities to realize desired personal benefits (Ibrahim and Cordes, 2008; Leitner and Leitner, 1996). Here, benefits are defined as (1) improved condition, (2) reduction of an undesired condition, and (3) desired condition (Driver, 2009). This study considers desired conditions, assuming that desired benefits could be identified by the assessment of visitors' recreational experiences as a reason for coming to Paklenica National Park. In Paklenica National Park, the most commonly pursued naturebased tourism activities are hiking and rock climbing, followed by sightseeing, wildlife viewing, visiting cultural and historical sites and picnicking (Lukač and Šikić, 2004; Šikić, 2007). Based on data gathered from regular observational visitor monitoring surveys conducted by Park staff, Jović (2004) revealed that more than $90 \%$ of individual visitors prefer to participate in the two first-mentioned activities. Visitors' desired benefits have also been investigated. Using a theory-testing approach, Barić, Anić, Tončić and Macias Bedoya (2015) tested the model of five hypothesised benefit dimensions (i.e., enjoy nature, novelty and learning, socializing, escape and solitude and personal achievement) comprised of eighteen motivational statements on a general visitor sample. They found a satisfactory data fit for the model with correlated benefit dimensions and showed that benefits Escape and solitude, Enjoy nature and Novelty and learning were rated as the most important for Park visitors. Moreover, their results indicated that Park visitors were more likely to perceive desired benefits through the wider prism of their positive mutual correlations rather than considering the benefits as self-sufficient and independent units. In addition, several publications, although descriptive in nature, revealed that Park visitors are predominantly foreigners, young to middle aged, welleducated and with higher than average income (Barić, 2011; Jonge, 2010; Tomljenović and Marušić, 2007). Similar visitors' characteristics were also found in other studies related to tourism in natural settings (Cheung and Fok, 2014; Kerstetter, Hou and Lin, 2004; Fennell, 2007; Holden and Sparrowhawk, 2002; Marques, Reis and Menezes, 2010; Wight, 1996).

As do many nature-based tourism attractions, Paklenica National Park appeals to different types of visitors whose activity preferences, profiles and hence needs, widely differ and who thus do not respond homogeneously to marketing activities (Kerstetter, Hou and Lin, 2004; Fennell, 2007; Mehmetoglu, 2007). The holistic understanding of recreational uses stands as a priority for the sustainable and effective management of protected areas (Hornback and Eagles, 1999; Pigram and Jenkin, 2006). The availability of recreational activities is an important criterion for visitors' destination choice and might reflect differences in visitors' socio-demographics, travel characteristics and behavioural patterns (Mehmetoglu, 2007; Morrison and Sung, 2000; Ryan and Sterling, 2001; UNWTO, 2007). Hence, for definition and planning of effective recreation management strategies, marketing and/or operations, it seems critical to provide Park managers with a more heterogeneous perspective on visitors, their engagement in recreational activities and their needs. Activitybased segmentation involves portioning the market into smaller and more homogeneous subsets or segments that can then be targeted in the same fashion because of their similar activity preferences (UNWTO, 2007). Segmentation analysis based on visitors recreational activities might assist Park managers to understand the demand side in a more complete manner. Moreover, such analysis might contribute not only to enhancement of market awareness but also to drawing more-accurate conclusions about how natural resources are used (Bild and Opp, 2013; Hsieh, O'Leary and Morrison, 1992; Morrison, Hsieh and O'Leary, 1994; Ryan and Sterling, 2001). 
This study focuses on activity-based segmentation of specific subgroups of visitors, specifically visitors to Paklenica National Park.

\section{Theoretical framework and literature review}

Market segmentation refers to the process of partitioning the market into homogeneous segments, profiling and analysing of extracted segments and developing and formulating an appropriate marketing strategy for each segment (Walker and Walker, 2011). Most often, the basis for segmentation involves socio-demographic (e.g., age, gender, education, and income), geographic (e.g., place of residence), psychographic (interests, opinions, activities, and travel motivation) and behavioural (benefits sought, attitudes, and usage rate) criteria (Kotler, Wong, Saunders and Armstrong, 2004). The selection of bases greatly depends on study aim and type and on the managerial demands of the considered destination (Wedel and Kamakura, 2000). For segmentation to be efficient, segments should be characterised by a high level of homogeneity, be measurable, accessible, competitive, compactible, durable and managerially useful (UNWTO, 2007). There are two basic segmentation approaches, a priori/common-sense and a posteriori/data driven (Dolnicar, 2004; Mazanec, 2000). The former refers to description and profiling of grouping criteria that are known or specified beforehand (e.g., interest group or specific variables). This approach is considered simpler because it lacks methodological pitfalls (Dolnicar and Grun, 2008). The latter approach is used when there are no prior insights about a distinct group in advance. Here, to extract homogeneous and mutually distinct segments, groupings are searched out by application of statistical techniques (i.e., factor and/or cluster analysis) on empirical survey data. The resulting segments are then profiled using variables considered relevant for specific managerial demands and study aims (Dolnicar, 2002). When assuming that nature-based tourism is the starting point of a segmentation process, then, in the first case, the selection of one of its sub-segments (e.g., visitors to special areas) inherently refers to a common-sense approach. In the second case (i.e., analysis of selected interest groups), segmentation might be performed by using both mentioned approaches, in a separate or combined manner (Dolnicar, 2004). Thus, in the context of the present study, by the very selection of visitors of Paklenica National Park as a special interest group, a common-sense approach was conducted first, followed by a data-driven approach based on the ratings of importance of those activities in which visitors actually participated during a Park visit.

Early studies on classification of nature-based tourists largely focussed on development of conceptual and, to a certain extent, static typology schemes (Hvenegaard, 2002). For instance, using level of interest and physical rigor as a classification basis, Laarman and Durst (1987) distinguished between hard and soft nature tourists. Although the latter describes those individuals who only have a general idea about the nature of activities in which they engage, the former group refers to those subjects who can articulate specific information about such pursuits. Later, Lindberg (1991) expanded this "binary scheme" and suggested four types of nature tourists: (1) hard-core (i.e., scientific researchers or members of tours designed for education), (2) dedicated nature tourists (i.e., travel specifically to protected areas to participate in outdoor activities), (3) mainstream tourist (i.e., those who seek an unusual trip); and (4) casual nature tourists (i.e., those who partake of nature incidentally or as a part of a broader trip).

Because in recent decades wilderness and protected areas have become popular attractions for nature-based tourism, visitor market segmentation based on empirical datasets has attracted substantial attention among different research teams. To date, a wide range of segmentation criteria have been used to identify homogeneous visitor segments, including socio-demographic characteristics (Kruger, 2015; Meng and Uysal, 2008), travel motivations (Kerstetter, Hou and Lin, 2004; Farías Torbidoni, 2011; Marques, Reis and Menezes, 2010), benefit desired (Bricker and Kerstetter, 2002), values and attitudes (Cochrane, 2006; Mehmetoglu, 2005; Weaver and Lawton, 2002). However, to the authors' best knowledge, visitor activities have rarely been utilised as a grouping criterion 
(Hvenegaard, 2002; Mehmetoglu, 2007; Ryan and Sterling, 2001) although, in the general tourism literature, activity-based segmentation has attracted considerable attention as a more stable alternative to those segmentation studies exclusively based on cognitivenormative inputs (i.e., travel motivations; e.g., Hsieh, O'Leary and Morrison, 1992; Mumuni and Mansour, 2014; Sung, 2004).

Using a national park in northern Thailand as a case study, Hvenegaard (2002) empirically tested the level of congruency between interactive (i.e., researcher-based, respondentbased, and activity-based) and cognitivenormative (i.e., motivation-based) tourist typologies. Within the activity-based typology, he identified five distinct segments virtually polarised between two groups of visitors. The first group (i.e., highlights trekker and intensive visitor) was exclusively dedicated to physically challenging activities, showing less interest for other activities and Park features; whereas the second group (i.e., highlighted visitor, knowledgeable birder and generalist birder) was more inclined to less challenging physical activities, interpretation and viewing flora and fauna. Moreover, his study showed that, when compared with the motivation-based typology, the activity-based typology revealed greater consistency with a researcher based and respondent-based typology.

Driven by Hvenegaard (2002), Mehmetoglu (2007) segmented nature-based tourists at two wilderness areas in northern Norway according to trip activities, then examined whether the segments differed in terms of trip motivations, travel behaviour and socio-demographic characteristics. Three distinct segments were identified (i.e., culture-pleasure, nature and low-activity oriented). The segments differed significantly in terms of perceived importance of motivational domains of physical activities, mundane daily activities and social contact. In contrast, for the domains of nature, ego and novelty, the given ratings maintained a more balanced ratio among observed segments.

Despite the relatively small number of empirical works devoted to activity-based segmentation of visitors to protected natural settings, in many of the mentioned segmentation studies, visitors' activities were used as a segment descriptor (Marques, Reis and Menezes, 2010; Mehmetoglu, 2005; Tao, Eagles and Smith, 2010; Weaver and Lawton, 2002). For instance, Weaver and Lawton (2002) showed that recreational activities could be useful indicators for identification of the characteristics of hard and soft ideal types on the ecotourism spectrum. Specifically, they found that hard eco-tourists prefer to be physically active and challenged, seeking more-personal experiences. Moreover, such tourists are characterised as being environmentally committed, with a strong preference for specialised and longer trips in small groups. Conversely, soft eco-tourists display characteristics such as engagement in less challenging physical activities and emphasis on interpretation, large group composition, multipurpose trips, short length of stay and moderate environmental commitment. The structured eco-tourists partially resemble both poles - hard, in terms of being physically active and environmentally committed, and soft in terms of characteristics such as emphasis on interpretation and multipurpose and short trips within larger groups.

\section{Purpose and objectives of the study}

Although relatively extensive research has been performed on visitor market segmentation in wilderness and protected natural settings, there remain very few publications in the literature that specifically refer to segmentation of national park visitors, using their trip activities as segmentation criteria. Therefore, this research will add to the current body of knowledge by addressing this particular issue.

By using Paklenica National Park as a case study, the main purpose of this applied research is to demonstrate the utility and practical application of activity-based visitor segmentation in protected areas (e.g., national parks). The principal objectives of this research are the following:

(i) to segment Paklenica National Park visitors into comparable and managerially useful activity-based subgroups.

(ii) to examine whether and to what extent activity-based segments differ in terms of rating 
the importance of benefits desired, sociodemographic characteristics,

travel behaviour and environmental commitment.

(iii) to assess inter-correlations between desired benefit dimensions with respect to each extracted segment and examine whether these independent correlation coefficients differ significantly.

(iv) to provide a series of practical management implications from research findings and concrete recommendations for developing more-effective visitor management strategies.

\section{Materials and methods}

Case study

Paklenica National Park $\left(\varphi: 44^{\circ} 18^{\prime} \mathrm{N} ; \lambda: 44^{\circ}\right.$ $25^{\prime} \mathrm{E}$ ), with an area of approximately $95 \mathrm{~km}^{2}$, stretches along the coastal slope of the southern part of the Biosphere Reserve "Velebit Mountain" on the north-east Adriatic Sea. Established in 1949, it is the second oldest of the eight national parks in the Republic of Croatia. The Park is managed and coordinated by the National Park Paklenica Public Institution under the jurisdiction authority of the Ministry of Culture of Republic of Croatia. Due to its immense wealth of karst relief forms, forest landscapes (Marasović, 2004; Perica et al., 2004) and remarkable richness of endemic species (Alegro, 2004; Lukač, 2004) the Park is identified as a focal point of international significance within the Natura 2000 Ecological network. Hosting 100,000 visitors per year (Croatian Bureau of Statistics, 2014), the Park is a well-recognised international nature-based tourism destination. Visitor uses of natural resources for tourism and recreation purposes are managed throughout a designed zone system based on a model of concentrated recreational uses. This model was chosen to facilitate control of the potentially negative effects caused by visitor activities within specific Park areas (Šikić, 2007). The recreational zone occupies $16.8 \%$ of the total Park surface. Covering the entire area around Velika Paklenica canyon, it extends from the main entrance on the southern border to mountain shelter Struge located in the far hinterland. With more than $50 \mathrm{~km}$ of relatively steep hiking trails and approximately 400 climbing routes, the park is particularly attractive for visitors inclined to nature-based activities such as hiking, wildlife watching or rock climbing (Lukač and Šikić, 2004). Over $95 \%$ of all visitors are concentrated within this zone (Šikić, 2007). The second official entrance, placed at the mouth of the canyon Mala Paklenica, is far less frequently used due to a higher level of conservation, hard terrain and lack of recreational facilities. The rest of the Park-designated zones cover isolated mountainous parts of the Park characterised by a higher level of biodiversity conservation, with no or very restricted visitor assess (Jović, 2004; Šikić, 2007).

When choosing Paklenica National Park as an appropriate case study, two reasons were considered the most important. The first refers to limitations in sampling strategies of naturebased tourists highlighted in prior studies. Specifically, the selection was, to a certain extent, driven by Mehmetoglu (2007) study, justified his case study by referring to an observation by Weaver and Lawton (2002) that in many segmentation studies addressing nature or eco-tourists, the samples are often based on general tourists (e.g., Palacio and McCool, 1997) instead of focussing on those visitors whose main characteristics might be designated nature based. Because the Paklenica National Park attracts a relatively specific type of visitor predominantly devoted to a relatively narrow scope of recognised naturebased activities (e.g., hiking and rock climbing) and, besides conservation of biodiversity, is aimed at providing a range of nature-related experiences, it was assumed that by its selection, the aforementioned generalisations could be partially avoided. The second reason refers to current management demands of the Park agency. Specifically, according to the tenyear Paklenica National Park Management Plan, continuous visitor monitoring using standardised questionnaires is highlighted as a key objective (Šikić, 2007). However, to date, there has been very little information collected about visitors' characteristics and needs, with the result that stated objectives remain empirically unevaluated. Therefore, this research will shed light on a more heterogeneous perspective in visitor monitoring and thus directly aid Park managers to evaluate empirically at least a basic level of performance in visitor management. 


\section{Sample and data collection}

The population for this study comprised 342 visitors, 18 years and older, who visited Paklenica National Park in the month of August 2013. Samplings were operationalised at the mouth of canyon Velika Paklenica every day from 10 a.m. to 2 p.m. and from 6 p.m. to 8 p.m., including weekends and national holidays. The sampling location and period were recommended by Park managers as the most appropriate due to the highest visitor flow. Data were gathered by means of a selfadministered questionnaire using a face-to-face approach. Due to financial restrictions, the questionnaire was provided in only two languages, English and Croatian. Each 10minute time interval, the next arriving visitor was approached and asked to participate in the survey. To avoid affecting overall enjoyment when entering the Park, visitors were approached on their way out. Visitors under 18 years of age were not included in the survey. When groups were approached, only one visitor was randomly sampled. No other respondents were surveyed unless the selected visitor did not complete the questionnaire. On average, each respondent took approximately 15 minutes to complete the questionnaire. In total, 352 questionnaires were collected of which $97.1 \%$ (342) were usable for further analysis. Visitors expressed a noticeably high level of willingness for collaboration, with only three visitors declining to join the survey.

\section{Instrument}

The questionnaire was partitioned into three main parts. In the first part, visitors were asked to rate the importance of those activities in which they actually participated, and thereafter to indicate the importance of desired benefits as a reason for their decision to visit Paklenica National Park. Both ratings were operationalised using the 5-point Likert scale ranging from one (1 - not at all important) to five (5 - extremely important). According to suggestions provided by Park managers, the list of selected activities was drawn from the official Management Plan of Paklenica National Park (Šikić, 2007). The desired benefit dimensions were derived based upon a previous study (Barić, Anić, Tončić and Macias Bedoya, 2015), whose findings provided confirmatory evidence that the used benefit dimensions are relevant to a general visitor sample in Paklenica National Park (i.e., X2= $376.50, \quad x 2 / d f=3.01, \quad$ RMSEA $=0.08 ; \quad$ SRMR $=.08$ ). The second part contained the questions about visitors' travel behaviour and their environmental commitment. For clarity, the second part was additionally divided into four subsections. The first one (i.e., Pre-visit information) included three questions addressing the purpose of the visit, decision time and length of planned visit. The second sub-section, labelled Site information, comprised four questions (e.g., group composition). In the third sub-section, visitors were asked about the place and type of accommodation, whereas the fourth subsection was devoted to visitors' affinity for visiting protected areas and membership in nature-related clubs or associations. All questions were closed ended. The third part of the questionnaire generated information about visitors' socio-demographic characteristics, such as place of origin, age, gender, level of education and income.

\section{Data analysis}

Collected data were transformed and coded using the Statistical Package for the Social Sciences 13.0 (SPSS). First, to identify target visitor activity groups, hierarchical (Ward's method) and non-hierarchical (K-mean) cluster procedures were used. Second, to explore difference between segments in terms of participated activities and desired benefit dimensions, independent sample t-test and multivariate analysis of variance (MANOVA) with Bonferroni correction were performed. Third, to assess the relationships between desired benefit dimensions, two separate analyses were employed. A Pearson correlation coefficient $(r)$ was calculated for each target group to assess separately the relationships between desired benefits. To examine whether the correlations for the target groups differed significantly, a test of the difference between independent correlation coefficients was performed (Preacher, 2002). Fourth, cross tabulations and a Chi square Goodness-of-fit test at a $95 \%$ accuracy level were used to assess the differences between segments with respect to socio-demographic and travel behaviour variables. In cases in 
which categories were pooled for analyses, resulting in degrees of freedom $(\mathrm{df})=1$, the Yates Correction for Continuity (X2c) was used (Pallant, 2011).

\section{Results}

\section{Segmentation procedure}

To segment visitors to Paklenica National Park according to a rating of importance of participated activities, a cluster analysis was conducted (Figure 1). Given that the number of segments was not known in advance, Ward's hierarchical cluster procedure with squared Euclidian was used first to determine the most appropriate number of segments. The results of group membership, agglomeration coefficient and associated dendrograms suggested four clusters. Accordingly, a non-hierarchical K- means cluster method was employed to additionally test for two, three and four solutions. A solution with two clusters was deemed most appropriate because the obtained segments displayed the most satisfactory characteristics in terms of interpretability, measurability and managerial applicability. The result of an independent sample t-test revealed that segments' mean score significantly differed on five of six activity dimensions at the .001 probability level (Table 1). Extracted segments were named according to the level of physical intensity. The first segment represented $60.8 \%$ of the total sample and was labelled Activists because it comprised those visitors dedicated exclusively to rock climbing activities and who showed minor or no interest in other recreational

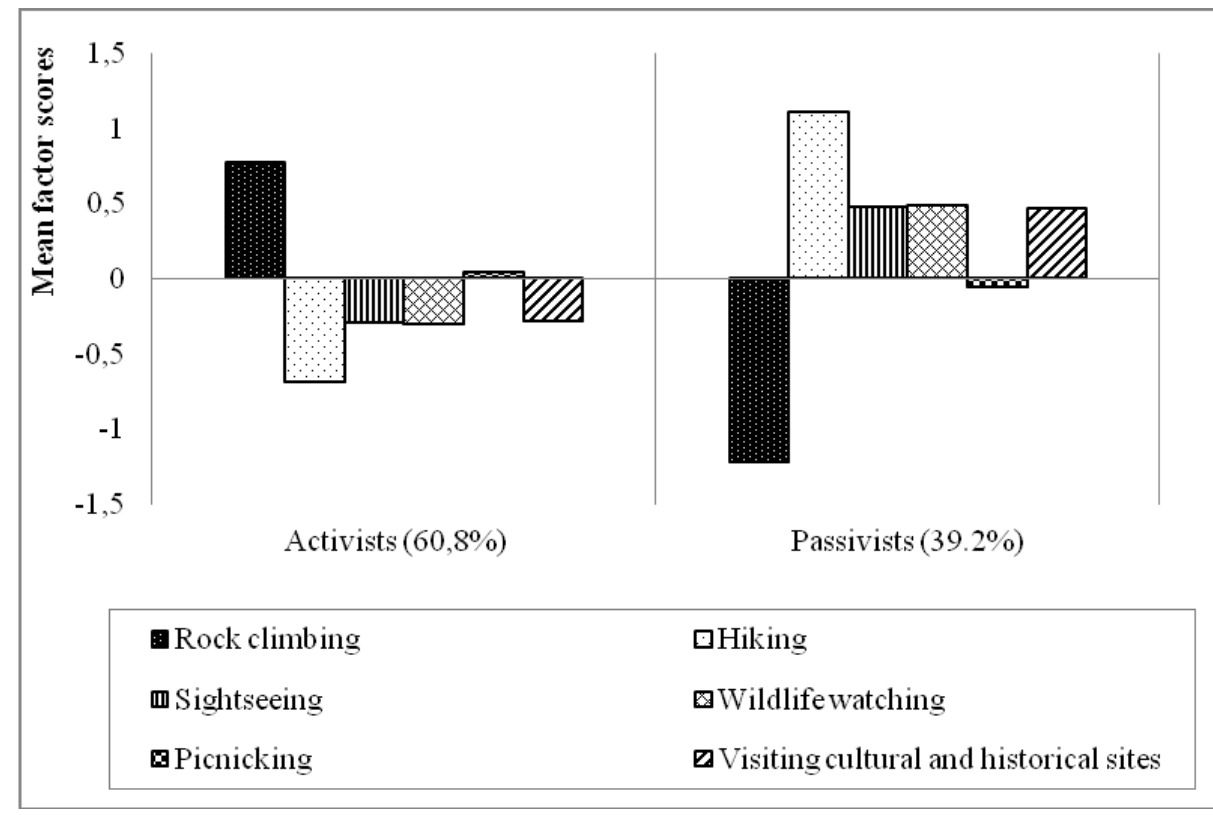

Figure 1. Distribution of mean scores by segments

Table 1. Mean score comparison of activity dimensions by segments

\begin{tabular}{|c|c|c|c|c|}
\hline Trip activities & Segments & & df & $\mathrm{t}$ \\
\hline & Activists & Passivists & & \\
\hline Rock climbing & 0.77 & -1.22 & 205 & $67.30^{* * *}$ \\
\hline Hiking & -0.69 & 1.10 & 329 & $38.12^{* * *}$ \\
\hline Sightseeing & -0.30 & 0.47 & 215 & $6.91^{* * *}$ \\
\hline Wildlife watching & -0.30 & 0.48 & 193 & $6.86^{\star \star *}$ \\
\hline Picnicking & 0.04 & -0.06 & 340 & 0.91 \\
\hline Visiting cultural and historical sites & -0.29 & 0.46 & 174 & $6.31^{\star * *}$ \\
\hline
\end{tabular}

Note: ${ }^{* \star *}$ Sianificant at $\mathrm{D}<0.001$ 
activities. The second segment included $39.2 \%$ of respondents. In contrast to the first group, these visitors participated in a wider scope of less challenging activities, of which hiking received the highest mean score, followed by accompanied activities sightseeing, wildlife watching and visiting cultural and historical sites. Consequently, this group of visitors was named Passivists.

Segment differences in socio-demographic characteristics

Segment differences in socio-demographic characteristics are presented in Table 2. The results of the Chi square test indicated no significance differences between segments in terms of nationality, gender, age or monthly household income. Foreign visitors predominated within both segments, maintaining an almost balanced ratio of over
$80 \%$. Male respondents slightly outnumbered females in both the total sample $(52.3 \%)$ and the Activists group (56.7\%). The overall age distribution showed a noticeable skew towards the age range of $22-34$ years $(60.3 \%)$. Furthermore, approximately $68 \%$ of Activists and Passivists had net monthly household income between $€ 1000-2500$. A significant difference was, however, found in terms of level of education $(p<.05)$; more highly educated visitors prevailed within Passivists $(79.8 \%)$.

Segment differences in the perceived importance of desired benefit dimensions An inspection of mean scores (Table 3) indicated that Activists provided the highest score for benefit dimensions Escape and solitude, followed by Enjoy nature and Personal achievement. For this segment, the desired

Table 2. Segment differences in socio-demographic characteristics

\begin{tabular}{|c|c|c|c|c|c|}
\hline & & $\begin{array}{l}\text { Activists } \\
\%\end{array}$ & $\begin{array}{l}\text { Passivists } \\
\%\end{array}$ & $\begin{array}{l}\text { Total sample } \\
\%\end{array}$ & $\mathrm{x}^{2}$ \\
\hline \multirow[t]{3}{*}{ Nationality $^{1}$} & & & & & .144 \\
\hline & Domestic & 18.3 & 16.7 & 17.6 & \\
\hline & Foreign & 81.7 & 83.3 & 82.4 & \\
\hline \multirow[t]{3}{*}{ Gender $^{1}$} & & & & & 2.255 \\
\hline & Female & 43.3 & 52.3 & 46.8 & \\
\hline & Male & 56.7 & 47.7 & 53.2 & \\
\hline \multirow[t]{5}{*}{ Age } & & & & & 2.372 \\
\hline & Under 21 & 8.7 & 6.1 & 7.6 & \\
\hline & $22-34$ & 62 & 57.6 & 60.3 & \\
\hline & $35-44$ & 16.3 & 18.9 & 17.4 & \\
\hline & 45 and older & 13 & 17.4 & 14.7 & \\
\hline \multirow[t]{3}{*}{ Education ${ }^{1}$} & & & & & $7.643^{*}$ \\
\hline & High school degree & 35 & 20.2 & 29.1 & \\
\hline & University degree & 65 & 79.8 & 70.9 & \\
\hline \multirow[t]{5}{*}{ Household income } & & & & & 3.474 \\
\hline & Less than $€ 1000$ & 32.2 & 30.5 & 31.6 & \\
\hline & $€ 1001-2500$ & 44.8 & 38.1 & 42.2 & \\
\hline & $€ 2501-5000$ & 16.9 & 20.3 & 18.3 & \\
\hline & More than $€ 5001$ & 6 & 11 & 8 & \\
\hline
\end{tabular}

Notes: * Significant at $p<0.05 ;{ }^{1}$ Yates Continuity Correction $(2 \times 2)$; Percentages in bold indicate the observed frequencies are greater than expected under the respective null hypothesis.

Table 3. Descriptive statistics for the importance of desired recreational benefits with respect to each segment

\begin{tabular}{|c|c|c|c|c|c|c|}
\hline \multirow{2}{*}{$\begin{array}{l}\text { Desired benefit } \\
\text { dimensions }\end{array}$} & \multicolumn{2}{|c|}{ Activists } & \multicolumn{2}{|c|}{ Passivists } & \multicolumn{2}{|c|}{ Total sample } \\
\hline & Mean & $\begin{array}{l}\text { Standard } \\
\text { deviation }\end{array}$ & Mean & $\begin{array}{l}\text { Standard } \\
\text { deviation }\end{array}$ & Mean & $\begin{array}{l}\text { Standard } \\
\text { deviation }\end{array}$ \\
\hline Enjoy nature & 3.79 & 0.65 & 4.07 & 0.60 & 3.91 & 0.64 \\
\hline Novelty and learning & 3.23 & 0.88 & 3.74 & 0.73 & 3.43 & 0.86 \\
\hline Socializing & 3.31 & 0.92 & 2.98 & 0.99 & 3.19 & 0.96 \\
\hline Escape and solitude & 4.17 & 0.73 & 4.02 & 0.82 & 4.13 & 0.77 \\
\hline Personal achievement & 3.70 & 0.73 & 3.34 & 0.76 & 3.56 & 0.75 \\
\hline
\end{tabular}


benefit Novelty and learning was the least important. Conversely, for Passivists, Enjoy nature was the highest-ranked desired benefit, followed by Escape and solitude and Novelty and learning. The desired benefit Socializing received the lowest mean score.

To ascertain whether the segments differed in terms of valuing the importance of benefit dimensions, a multivariate analysis of variance (MANOVA) was performed because it is considered an appropriate technique when dependent variables are correlated (Hair, et al., 2006). As Table 4 shows, a statistically significant difference between the two segments was recorded with respect to combined desired benefit dimensions, $F$ $(5,324)=20.4, p<0.001$; Wilks' Lambda=0.76. Consequently, a separate multivariate interaction effect was examined to identify in which particular desired benefit dimension the two groups differed significantly. Using a Bonferroni adjusted alpha level of 0.01 , results indicated that Activists and Passivists differed significantly in four of five benefit dimensions: Enjoy nature $\mathrm{F}(1,328)=15.692 ; \quad \mathrm{p}<0.001$, $\eta 2 \mathrm{p}=0.046 ; \quad$ Novelty and learning $F(1,328)=30.303 ; \quad p<0.001, \quad \eta 2 p=0.085$; Socializing $\quad F(1,328)=9.071 ; \quad p<0.01$, $\eta 2 \mathrm{p}=0.027$; and Personal achievement $F(1,328)=18.919 ; \quad p<0.001, \quad \eta 2 p=0.05$. No significant difference was found for the benefit dimension Escape and solitude.

Differences between independent correlation coefficients for desired benefit dimensions among segments

The magnitudes of inter-correlations between desired benefit dimensions with respect to target activity groups are presented in Table 5 . For Activists, statistically significant correlations were recorded between all desired benefit dimensions, whereas for Passivists, that was not true for correlations between dimensions Enjoy nature and Socialising $(r=0.073, p=$ 0.416 ) or Enjoy nature and Escape and solitude $(r=0.10, p=0.260)$. To investigate whether the magnitude of correlations for the two segments differed significantly, the test of the difference between two independent correlation coefficients was performed. The results revealed a significant difference between correlation coefficients of the two groups in terms of correlations between dimension Enjoy nature and dimensions Novelty and learning $(p<0.01)$, Socialising $(p<0.01)$ and Escape and solitude $(p<0.01)$. However, significant differences in correlation coefficients were also observed in terms of correlation between benefit dimensions Socialising and Escape and solitude $(p<0.001)$.

\section{Segment differences in travel behaviour and environmental commitment}

Segment differences in travel behaviour and environmental commitment are illustrated in Table 6. A Chi square test revealed significant differences between segments in terms of trip purpose, decision time and duration of planned visit at the .001 probability. For more than half of Activists (57.1\%), Paklenica National Park was the main purpose of the trip, and a very small number of them visited the Park unprepared $(3.3 \%)$. In contrast, only $9 \%$ of Passivists stated that the Park was the main purpose of their trip, and approximately onethird arrived without specific preparation $(36.4 \%)$. Visiting the Park as a part of a larger trip was more pronounced among Passivists $(55.2 \%)$ than among Activists (38.5\%). The results also indicated that Activists showed a greater tendency to plan their trip in advance,

Table 4. MANOVA results for differences between segments in terms of benefit dimensions

\begin{tabular}{lllll}
\hline Desired benefit dimensions & Sum of Squares & $\mathbf{d f}$ & $\mathbf{F}$ & $\mathbf{n}_{\mathbf{p}}^{2}$ \\
\hline Enjoy Nature & 6.235 & 1 & $15.692^{\star \star \star}$ & 0.046 \\
Novelty and learning & 20.211 & 1 & $30.303^{* \star *}$ & 0.085 \\
Socialising & 8.196 & 1 & $9.071^{\star \star}$ & 0.027 \\
Escape and solitude & 1.741 & 1 & 2.942 & 0.009 \\
Personal achievement & 10.325 & 1 & $18.919^{\star \star \star}$ & 0.05 \\
\hline Multivariate F & 20.390 & & & \\
Wilks' Lambda & 0.761 & & & \\
\hline Note: ** Significant at $\mathrm{p}<0.01 ;{ }^{* * *}$ Significant at $\mathrm{p}<0.001$ & & &
\end{tabular}


predominantly a week before arrival (66.8\%), and preferred to visit the Park more than one day $(90.4 \%)$. Conversely, Passivists were more

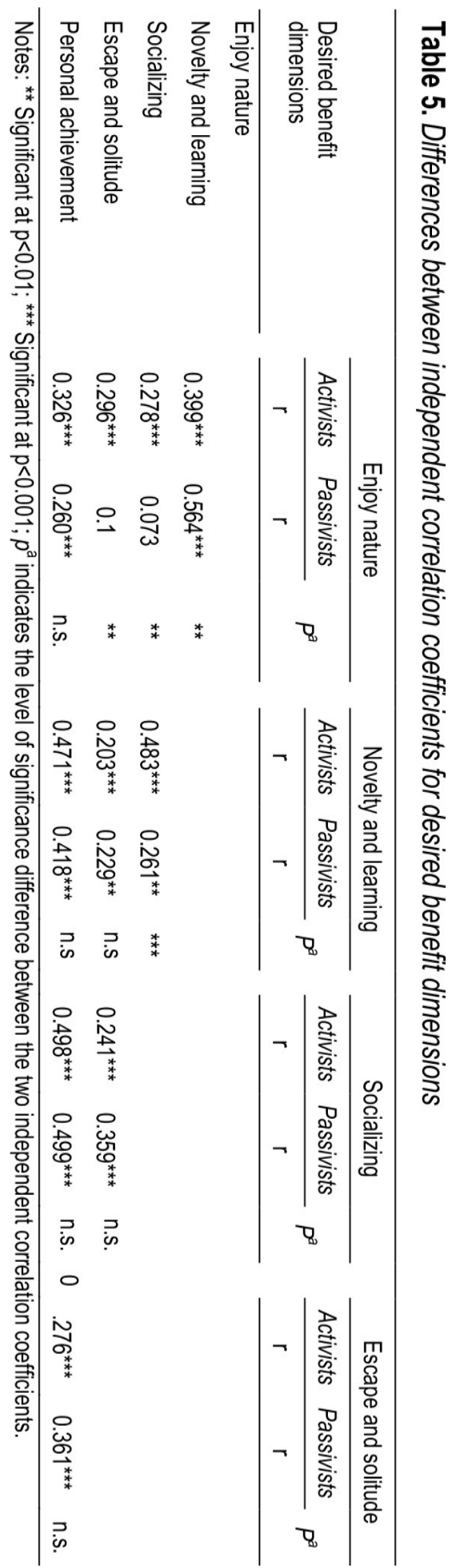

inclined to plan the visit within the week of arrival (59.6\%), staying only for one day (76.5\%). Furthermore, segments differed significantly with respect to frequency of visits $(p<0.001)$, group composition $(p<0.05)$ and length of daily visit $(p<0.001)$. First-time visitors were more represented among Passivists $(75 \%)$. In general, more than one-third of Activists (39.5\%) and Passivists (35.1\%) visited the Park with their partners. However, Activists were more likely to visit the Park with a group of friends, whereas Passivists showed a greater tendency to visit the Park with family. Unlike the Activists, who were more likely to stay in the Park for a whole day, Passivists preferred to stay only for half a day. Significant differences between segments were also found in terms of place $(p<0.001)$ and type $(p<0.01)$ of accommodation. Although the majority of respondents $(81.2 \%)$ preferred to overnight near the Park in Starigrad-Paklenica Municipality, a noticeably higher percentage was observed among Activists (90\% vs. $66.9 \%$ for Passivist). The results on the type of accommodation indicated that Activists preferred relatively primitive types of accommodation, whereas Passivists were more likely to choose more-luxurious overnight accommodations. Yet, significant differences between segments were recorded in terms of frequency of annual visits to protected areas $(p<0.01)$ and membership in nature-related clubs and associations $(p<.001)$. With respect to the former, the general sample showed considerably high affinity for visiting protected areas $(91.2 \%)$. However, a separated perspective indicated that Passivists were more likely to visit protected areas up to ten times per annum. In contrast, affinity to visiting protected areas more than ten times was more pronounced within Activists. With respect to membership in nature-related clubs or associations, data indicated that among those visitors who declared membership (46\%), the share of Activists was almost double those of Passivists, i.e., $54.8 \%$ vs. $32.3 \%$, respectively.

\section{Discussion}

The main idea of this applied research was to segment visitors of Paklenica National Park by activities to investigate differences among the visitors with respect to benefits desired, travel behaviour, environmental commitment and 
Segmenting protected area visitors by activities: A case study in Paklenica National Park, Croatia.

socio-demographic characteristics. The general findings provide further support to earlier studies in the field, which found that visitors to wilderness and protected natural areas are not a homogeneous group (e.g., Marques, Reis and Menezes, 2010; Ryan and Sterling, 2001).
Although the initial results of Ward's hierarchical clustering procedure suggested four clusters, we decided to explore several additional cluster solutions to identify and present segments that will be not only comparable and measurable but also

Table 6. Segment differences in travel behaviour and environmental commitment

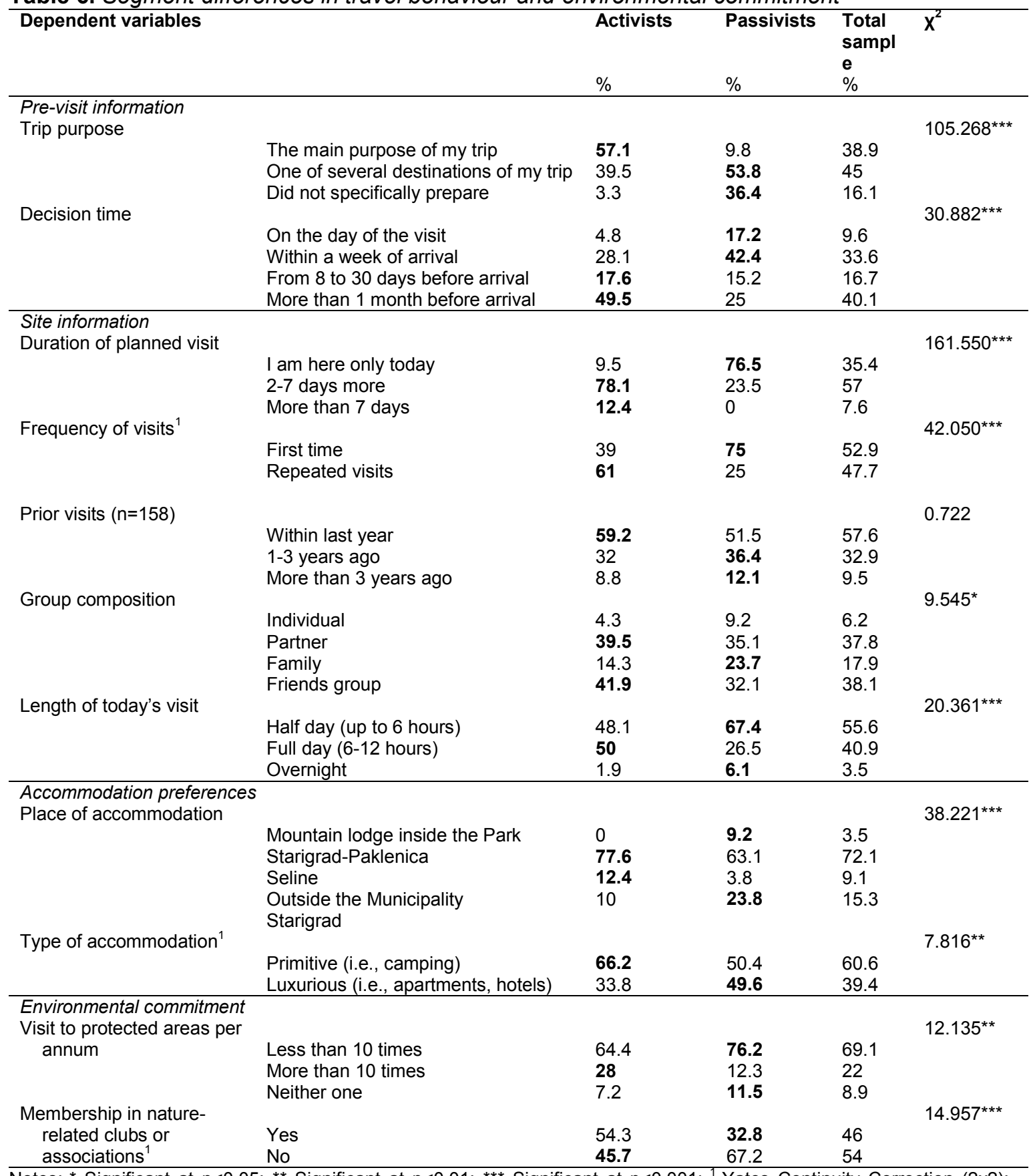

Notes: ${ }^{*}$ Significant at $\mathrm{p}<0.05 ;{ }^{* *}$ Significant at $\mathrm{p}<0.01 ;{ }^{* \star *}$ Significant at $\mathrm{p}<0.001 ;{ }^{1}$ Yates Continuity Correction $(2 \times 2)$;

Percentages in bold indicate the observed frequencies are greater than expected under the respective null hypothesis. 
understandable and useful to Park authorities in the process of future management. Consequently, two activity-based segments of Paklenica National Park visitors were identified: Activists and Passivists. The results indicated that in comparison to Passivists, Activists showed a considerably higher degree of dedication in terms of intensity and spectrum of engaged activities. Placed in the context of Laarman and Durst's (1987) conceptual typology of nature-based tourists ("hard" vs. "soft"), the findings suggest that when considering both physical rigour and level of interest, Activists displayed "hard" whereas Passivists gravitated more to the "soft" pole of the continuum.

Concerning socio-demographic characteristics, the general sample revealed that Paklenica National Park visitors were predominantly foreigners, male, middle to young aged (i.e., 25-34 years), well-educated and with a high level of income. These findings are consistent with those of Tomljenović and Marušić (2007) with respect to place of origin; Bricker and Kerstetter (2002), Cheung and Fok (2014) and Holden and Sparrowhawk (2002) in terms of age range; Kerstetter, Hou and Lin (2004) and Kruger (2015) with respect to level of education; and Marques, Reis, and Menezes (2010) in terms of household income. When segments were compared, observed findings additionally supported the notion of a limited and weak role of socio-demographic descriptors in predicting the behavioural patterns of distinct types of visitors (Bild and Opp, 2013; Mehmetoglu, 2007; Zins, 1999). Specifically, a significant difference was recorded only with respect to level of education, in which higher-educated respondents were more represented among Passivists and vice versa. The recorded difference, to a certain extent, could be because the shares of elderly visitors and those with higher incomes were found to be greater among Passivists than among Activists. This finding mirrors those of earlier studies in the field, which revealed that visitors' level of education positively correlates with their age and household income (Kruger, Saayman and Saayman, 2010; Fredman, 2008; Wight, 1996). Although segments did not differ significantly, it is interesting to note the considerable bias observed between domestic and foreign visitors within both activity segments. Specifically, the overall number of foreign visitors was sevenfold higher than the number of domestic visitors $(82.3 \%$ vs. $17.4 \%$, respectively). This empirical evidence supports previous studies whose findings also indicated that Paklenica National Park stands as a recognised international nature-based tourism destination (Jović, 2004; Tomljenović and Marušić, 2007). However, findings provide further support to the general notion that protected areas are important legal tools for the regional development of tourism in natural settings (Puhakka, 2008). Moreover, the share of foreign visitors recorded in this study is consistent with data extracted from the Croatian Bureau of Statistics (2015), in which it was observed that, of approximately 1000000 visitors who have visited the Park since 2000 , slightly more than $83 \%$ were foreign. This statistic suggests that the present survey sample might be considered representative of the population that visits Paklenica National Park.

In contrast to socio-demographic descriptors, preferences towards importance of benefit desired revealed more-noticeable differences among segments. Specifically, findings indicated that segments differed significantly with respect to four of five desired benefit dimensions. A homogeneous ranking pattern was observed only for rating the importance of the Escape and solitude benefit, which was, in fact, the highest ranked dimension overall. To a certain extent, it was reasonable to expect such a high and similar scoring of benefit Escape and solitude because the sampling was undertaken in the peak of the tourist season in the month of August, when a majority of foreign respondents, who prevailed in the sample, were on vacation. In accordance with this finding, previous studies have also demonstrated that, regardless the level of intensity of participated activity, escaping from everyday life or seeking solitude are generally perceived as important and, in a certain sense, universal push factors for visitors to wilderness and protected area settings (Farías Torbidoni, 2011; Holden and Sparrowhawk, 2002; Pierskalla, et al., 2004). Furthermore, findings indicated that, to Passivists, experiencing and 
learning about nature was the most important benefit sought, whereas Activists ranked experiencing and learning about nature the second most important. These findings agree with results of other studies, which revealed that nature itself constitutes a core reason for visitors to protected natural settings (Kerstetter, Hou and Lin, 2004; Farías Torbidoni, Grau and Camps, 2005; Mehmetoglu 2007). In contrast, Activists were more inclined to seek benefits associated with personal achievement and socialisation. These findings are in agreement with Ryan, Hughes and Chirgwin (2000), who rightly noted that natural areas attract a variety of visitor profiles characterised by different needs and behaviour patterns. In the context of the current research, Activists were thus more likely to be involved in so-called affective nature experiences, i.e., those that allow them the opportunity to enjoy engaged activities or only admire the natural areas without exhibiting specific intellectual interest towards educational and learning experiences. Moreover, these findings corroborate the idea of Weaver and Lawton (2002), who suggested that experiences sought by visitors could best be understood when placed within the context of proposed characteristics of a hard-soft spectrum. From the perspective of this research, Activists mirrored the hard pole to a greater extent because they were more prone to seek personal experiences, whereas Passivists revealed a soft pole due to their noticeably greater interest towards interpretation experiences.

This study also contributes to the literature by further estimating differences in magnitudes of correlations among desired benefits considering each activity group. When segments have been examined separately, findings indicated that all correlations between desired benefit dimensions were positive and, with the exception of two, significant. The present results are managerially valuable because they provide specific evidence that visitors to Paklenica National Park perceive desired benefits more through the wider prism of their positive mutual relationship rather than by considering the benefits independent units. Thus, the results provide further support for Costello and Osborne (2005), who claim that in social science, it is more likely to find correlations among latent dimensions because behaviour is rarely subdivided into accurately packaged units that act independently amongst them. Furthermore, testing differences between independent correlation coefficients suggested that, to Passivists, desire for learning played a significantly greater role in enjoying and admiring nature. Conversely, to Activists, those benefits were associated with social affiliation and escaping. Furthermore, a significant difference among segments was also found in a correlation between the dimensions Socialising and Novelty and learning. To Park managers, this finding might suggest that, for Activists, social affiliation is considered a more prominent factor in gaining new knowledge.

In contrast to earlier studies (e.g., Mehmetoglu, 2007), segment differences in almost all aspects of the section related to visitors' travel behaviour proved that these descriptors have considerable capacity to differentiate distinct types of visitors to Paklenica National Park. When considering both travel behaviour and environmental commitment, findings once again clearly reflect Weaver and Lawton's (2002) proposed characteristics of a hard-soft ecotourism spectrum. In short, Activists resemble a hard pole because their trip was strongly attraction dedicated, specialised and far more planned in advance. Moreover, they stayed longer and preferred to visit the Park accompanied by their partner or a small group of friends. Yet, they preferred to stay in moreprimitive accommodations and showed a greater affinity towards visiting protected areas and supporting nature-related clubs or associations as members. In contrast, Passivists gravitated more to a soft pole because they were more likely to visit the Park as part of a multipurpose trip; thus, their visit was shorter and often unplanned. Moreover, a majority of them were first-time visitors who, in term of accommodation, expected a higher level of services and, comparing to Activists, they showed a lesser degree of environmental commitment.

\section{Conclusions and management implications} Using specific groups of nature-based tourists, visitors of Paklenica National Park, this study demonstrated that market segmentation based on activities in which visitors have participated 
might be deemed a confident and stable approach to explore the demand side in a more profound manner. In particular, providing a series of empirical evidence, the current research showed that Paklenica National Park is visited by two distinct groups of visitors whose profiles and needs are greatly determined by type and physical intensity of engaged recreational activities. Taken together, findings reinforced the notion that visitors to protected area natural settings do not behave as a homogeneous entity.

Note that Park authorities are currently laying the groundwork for development of a new Management Plan of Paklenica National Park. One of the key tasks Park managers faced refers to performance assessment, which inherently implies the revision and empirical evaluation of the objectives stipulated in the still relevant ten-year Management plan, created in 2006. As mentioned earlier, one of the highlighted objectives refers to development of comprehensive visitor monitoring programs, specifically calling for systematic gathering of data about visitors' basic profiles, recreational preferences, values and behavioural patterns (Šikić, 2007). However, due to financial restrictions and insufficient staff capacity, to date, such programs have not been developed. Given that, until this research, information being revealed was not previously available to the Park agency, the findings of this study have a number of important management implications and could be of great importance to Park managers in formulating more transparent, accurate and effective planning strategies for visitor management and for marketing programs in a broader sense.

First, socio-demographic descriptors have not shown a significant role in differentiation of distinct types of visitors. The only significant difference between segments was observed level of education. Nonetheless, obtained findings at the very least provide managers empirical confirmation that Paklenica National Park stands as an attractive destination for international, economically stable, well educated, relatively young and gender balanced population of nature-based tourists. In contrast, almost all aspects of travel characteristics do reveal close linkages to the target activity groups identified. This information might serve as reliable input not only for Park managers in developing more concrete marketing strategies but also for other relevant local stakeholders involved in planning and management of tourism in surrounded coastal settlements.

Second, insights provided into a heterogeneous perspective on desired benefits might assist Park managers to develop morespecific strategies for improving specific physical, social and managerial setting characteristics and thus enhance the opportunities for target activity groups to attain these desired benefits. For instance, results showed that, to Passivists, benefit Novelty and learning was more important than to Activists, who considered it least important. Moreover, when comparing independent correlation coefficients of the two activity groups, it was observed that, to Passivists, Novelty and learning correlated significantly higher with benefit Enjoy nature, suggesting that to them, gaining knowledge represented a more important factor in enjoying nature. One can rightly conclude that these results are logical, given that Activists mirrored those naturebased tourists with strong adventure aspirations and who thus sought personal rather than interpretation experiences. Although such a point of view is in accordance with some prior findings, in a certain context, it could have limited implications for Park managers, who primarily expect sound scientific and site-specific recommendations rather than coarse theoretical justification. Therefore, in accordance with findings obtained, a key management priority should be to focus on formulating and promoting specific interpretation and educational programmes, tightly associated with specific interests of identified target activity groups. One potential action could involve development of specific educational programmes for rock climbers (i.e., Activists). For example, such interpretation programmes could include specific guided tours, led by Park staff, aimed at educating rock climbers about the effects of climbing activities on the natural environment (i.e., karst relief forms). These suggestions have empirical support because results of current research revealed that Activists are well-educated 
tourists with considerable affinity to membership in nature-related associations. Moreover, results revealed that for this activity group, social affiliation is perceived as an important component in gaining new knowledge. Thus, by fostering such educational programmes, managers, in addition to enhancing interest towards learning in general, could directly influence visitors' behaviour in terms of raising awareness about the potential adverse effects of climbing activities on the Park's natural integrity. Moreover, development and implementation of such interpretation products could positively affect visitors' overall satisfaction and consequently lead to positive recommendations to others to visit the Park. Moreover, such products might not only contribute to the enhancement of Park financial viability but also be beneficial to local coastal residents, whose economic prosperity greatly depends upon Park visitors. Although the study focussed on the specific management demands of Paklenica National Park, the provided management implications, recommendations and practical suggestions go far beyond its boundaries. Therefore, it is hoped that this study could be of great interest for a wide spectrum of managers focussed on enhancing the sustainability of nature-based tourism in protected areas.

This research also has important implications for future research. Specifically, based on the current findings, it would be interesting to more accurately explore to what extent visitors labelled Activists and Passivists differ within their segment. Such sub-segmentation could provide Park managers with more concrete information about the "real" homogeneity of segments identified in this study. Another possible area of future research would be to merge visitor market segmentation with other performance analyses, such as importanceperformance analysis (IPA) or the service quality gap, to enhance the current understanding of how distinct visitors' subgroups perceive the quality of opportunities (i.e., facilities and services) provided by the Park agency.

Finally, the limitations of this study must be acknowledged. Due to financial restrictions, sampling was performed only in the month of
August, although the Park is visited from May until the end of October. Therefore, the results, although valuable and reliable, should not be generalised until continuous monitoring confirms the stability of the identified segments over a longer period.

\section{References}

Alegro, A. (2004) Biljni svijet NP "Paklenica". Paklenički zbornik 2, 35-44.

Arnberger, A., Eder, R., Allex, B., Sterl, P. and Burns, R C. (2012) Relationships between national-park affinity and attitudes towards protected area management of visitors to the Gesaeuse National Park, Austria. Forest Policy and Economics 19, 48-55.

Arnegger, J., Woltering, M. and Job, H., (2010) Toward a product-based typology for nature-based tourism: a conceptual framework. Journal of Sustainable Tourism 18(7), 915-928.

Balmford, A., Beresford, J., Green, J., Naidoo, R.., Walpole, M. and Manica, A. (2009). A global perspective on trends in naturebased tourism. PLoS biology, 7(6), [online]. Available at: <http://www. pubmedcentral.nih.gov/articlerender.fcgi?a rtid=2694281\&tool=pmcentrez\&rendertype =abstract $>$ [Accessed 28 May 2014].

Barić, D., Anić P., Tončić M. and Macias Bedoya A. (2015) Exploring visitors' desired benefits in Paklenica National Park, Croatia: Development, validation and management implication of measurement instrument. Journal of Outdoor Recreation and Tourism, 12, 59-63.

Barić, D. (2011) Visitor monitoring: management tool for sustainable nature based tourism in coastal protected areas. Case study: Paklenica National Park, Croatia. Unpublished MSc thesis. University of Cadiz.

Bild, C. and Opp, C. (2013) Tourist typology research in protected areas. Paper presented at $5^{\text {th }}$ Symposium for Research in Protected Areas, Mittersill, 10-12 June, 53-56.

Bricker, K.S. and Kerstetter, D.L. (2002) Ecotourists and Ecotourism: Benefit Segmentation and Experience Evaluation. Travel and Tourism Research Association [online]. Retrieved from: 
http://www.ttra.com/ pub/ uploads 1020.pdf [Accessed 28 June 2014]

Buckley, R. (2008) Ecotourism: Principles and practices. Cambridge: CAB International.

Centre for Responsible Travel (2015). The Case for Responsible Travel: Trends \& Statistics 2015. Available at: https://ecotourism.app.box.com/s/rxiyp657 44sqilmrybfk8mys3qvjbe9g [Accessed 05 May 2015].

Cessford, G. and Muhar, A. (2003) Monitoring options for visitor numbers in national parks and natural areas. Journal for Nature Conservation 11, 240-250.

Cheung, L.T.O. and Fok, L. (2014) The motivations and environmental attitudes of nature-based visitors to protected areas in Hong Kong. International Journal of Sustainable Development \& World Ecology 21, 28-38.

Cochrane, J. (2006) A typology of tourists to protected areas. Parks 16(2), 10-17.

Costello, A. and Osborne, J. (2005) Best practices in exploratory factor analysis: four recommendations for getting the most from your analysis. Practical Assessment Research \& Evaluation 10, 1-9.

Croatian Bureau of Statistics (2015). Croatian Bureau of Statistics. [online]. Available at: <http://www.dzs.hr> [Accessed 3 May 2015].

Diamantis, D. (1999) The Concept of Ecotourism: Evolution and Trends. Current Issues in Tourism 2 (2-3), 93-122.

Dolnicar, S. (2002) A review of data-driven market segmentation in tourism. Journal of Travel \& Tourism Marketing 12(1), 1-22.

Dolnicar, S. (2004) Beyond "commonsense segmentation": A systematics of segmentation approaches in tourism Journal of Travel Research 42(3), 244-250.

Dolnicar, S. and Grun, B. (2008) Challenging "Factor Cluster Segmentation". Journal of Travel Research 47(1), 63-71.

Driver, B. (2009) Managing to optimize the beneficial outcomes of recreation. State College: Venture Publishing.

Eurobarometer, (2014) Preferences of Europeans towards tourism, [online]. Available at: $<$ http://ec.europa.eu/public_opinion/flash/fl 392_sum_en.pdf.> [Accessed 19 March 2015].
Farías Torbidoni, E.I., Grau, H.R. and Camps, A. (2005) Trail Preferences and Visitor Characteristics in Aigüestortes i Estany de Sant Maurici National Park, Spain. Mountain Research and Development 25(1), 51-59.

Farías Torbidoni, E.I. (2011) Managing for recreational experience opportunities: The case of hikers in protected areas in Catalonia, Spain. Environmental Management 47(3), 482-496.

Fennell, D. (2007) Ecotourism.3rd ed. New York: Routledge

Fredman, P. (2008) Determinants of visitor expenditures in mountain tourism. Tourism Economics 14(2), 297-311.

Hair, J., Black, B. Babin, B., Anderson, R. and Tatham, R. (2006) Multivariate Data Analysis. 6th ed.. Upper Saddle River: Prentice-Hall.

Hall, C.M. and Boyd, S.W. (2005) Naturebased tourism in peripheral areas: Development or disaster? Clevedon: Channel View Publications.

Holden, A. and Sparrowhawk, J. (2002) Understanding the motivations of ecotourists: the case of trekkers in Annapurna, Nepal. International Journal of Tourism Research 4(6), 435-446.

Hornback, K.E. and Eagles, P.F.J. (1999) Guidelines for Public Use Measurement and Reporting at Parks and Protected Areas. Gland and Cambridge: IUCN.

Hsieh, S., O'Leary, J.T. and Morrison, A.M. (1992) Segmenting the international travel market by activity. Tourism Management 13(2), 209-223.

Hvenegaard, G.T. (2002) Using tourist typologies for ecotourism. Journal of Ecotourism 1(1), 7-18.

Ibrahim, H. and Cordes, K.A. (2008) Outdoor recreation: Enrichment for a life time. 3rd ed. Champaign: Sagamore Publishing.

Jonge, M. (2010) Carrying capacity assessment of the Paklenica National Park. Unpublished BSc thesis. University of Breda.

Jović, D. (2004) Visitors in Paklenica National Park. Paklenički zbornik 2, 129-134.

Kerstetter, D.L., Hou, J.S. and Lin, C.H. (2004) Profiling Taiwanese ecotourists using a behavioral approach. Tourism Management 25, 491-498. 
Kotler, P., Wong, V., Saunders J. and Armstrong, G. (2004) Principles of Marketing. 4th ed. London: Prentice Hall.

Kruger, M., Saayman, M. and Saayman, A. (2010) Expenditure-based segmentation of visitors to the Tsitsikamma National Park. Acta Commercii 10, 137-149.

Kruger, P.M. (2015) Segmenting visitors to the Addo Elephant National Park in South Africa based on educational level. African Journal of Hospitality, Tourism and Leisure 4(1), 1-20.

Laarman, J.G. and Durst, P.B. (1987) Nature travel in the tropics. Journal of Forestry 85(5), 43-46.

Leitner, M. J. and Leitner., S.F. (1996) Leisure enhancement. 2nd ed. New York: The Haworth Press.

Lindberg, K. (1991) Policies for maximizing nature tourism's ecological and economic benefits (International conservation financing project working paper). Washington: World Resources Institute, 1-37.

Lukač, G. (2004) Ptice gnjezdarice šireg područja NP "Paklenica." Paklenički zbornik 2, 95-100.

Lukač, G. and Šikić, Z. (2004) Preparations for the formulation of the management plan of Paklenica National Park. Paklenički zbornik 2, 155-160.

Marasović, Z. (2004) Tracing the development of vegetation in the permanent woodland area in Paklenica National Park. Paklenički zbornik 2, 55-64.

Marques, C., Reis, E. and Menezes, J. (2010) Profiling the segments of visitors to Portuguese protected areas. Journal of Sustainable Tourism 18(8), 971-996.

Mason, P. (2005) Visitor Management in Protected Areas: From "Hard" to "Soft" Approaches? Current Issues in Tourism 8, 181-194.

Mazanec, J. (2000) Market Segmentation. In: J. Jafari (ed.) Encyclopedia of Tourism. London: Routledge.

Mehmetoglu, M. (2005) A case study of naturebased tourists: Specialists versus generalists. Journal of Vacation Marketing 11(4), 357-369.

Mehmetoglu, M. (2007). Typologising naturebased tourists by activity-theoretical and practical implications. Tourism Management 28, 651-660.
Meng, F. and Uysal, M. (2008) Effects of gender differences on perceptions of destination attributes, motivations, and travel values: An examination of a naturebased resort destination. Journal of Sustainable Tourism 16(4), 445-466.

Morrison, A.M., Hsieh, S. and O'Leary, J.T., (1994) Segmenting the Australian domestic travel market by holiday activity participation. Journal of Tourism Studies 5(1), 39-56.

Morrison, M.A. and Sung, H.H. (2000) Adventure tourism. In: J. Jafari (ed.) Encyclopedia of tourism. New York: Routledge, p. 11.

Mumuni, A.G. and Mansour, M. (2014) Activitybased segmentation of the outbound leisure tourism market of Saudi Arabia. Journal of Vacation Marketing 20(3), 239252.

Newsome, D., Moore, S.A. and Dowling, R.K. (2002) Natural Area Tourism: Ecology, Impacts and Management. Clevedon: Channel View Publications.

Nyaupane, G.P., Morais, D.B. and Graefe, A.R. (2004) Nature Tourism Constraints. Annals of Tourism Research 31(3), 540555.

Orams, M.B. (1995) Towards a more desirable form of ecotourism. Tourism Management 16(1), 3-8.

Page, S.J. and Dowling, R.K. (2002) Ecotourism. Essex: Prentice Hall.

Palacio, V. and McCool, S.F. (1997) Identifying ecotourists in Belize through benefit segmentation: A preliminary analysis. Journal of Sustainable Tourism 5(3), 234243.

Pallant, J.F. (2011) SPSS Survival Manual: a step by step guide to data analysis. 4th ed. Crows Nest: Allen \& Unwin.

Perica, D., Marjanac, Z., Lončar, N. and Trajbar, S. (2004) O kamenicama, krškim bunarima i sigama na području NP "Paklenica." Paklenički zbornik 2, 9-16.

Pickering, C. and Weaver, D.B. (2003) Naturebased Tourism and Sustainability: Issues and Approaches. In: R. Buckley, C. Pickering and D. B. Weaver (eds.) Naturebased tourism, environment and land management. Cambridge: CABI Publishing, pp. 7-11. 
Pierskalla, C.D. et al. (2004) Understanding Relationships among Recreation Opportunities: A Meta-Analysis of Nine Studies. Leisure Sciences 26(2), 163-180.

Pigram, J.J. and Jenkin, J. (2006) Outdoor Recreation Management. 2nd ed. London \& New York: Routledge.

Preacher, K.J. (2002) Calculation for the test of the difference between two independent correlation coefficients [online]. Available at: <http://quantpsy.org> [Accessed 1 May 2015].

Puhakka, R. (2008) Increasing role of tourism in Finnish national parks. Fennia 186(1), 47-58.

Ryan, C., Hughes, K. and Chirgwin, S. (2000) The gaze, spectacle and ecotourism. Annals of Tourism Research 27(1), 148163.

Ryan, C. and Sterling, L. (2001) Visitors to Litchfield National Park, Australia: A Typology Based on Behaviors. Journal of Sustainable Tourism 9(1), 61-75.

Šikić, Z. (2007). Paklenica National Park. Management Plan. Starigrad-Paklenica: Ministry of Culture of the Republic of Croatia.

Sung, H.H. (2004) Classification of Adventure Travelers: Behaviour, Decision Making, and Target Markets. Journal of Travel Research 42(4), 343-356.

Sung, H.Y., Morrison, A.M. and O'Leary, J.T. (1997) Segmenting the adventure travel market: From the North American industry providers' perspective. Journal of Travel and Tourism Marketing 9(4), 1-20.

Swarbrook, J., Beard, C., Leckie, S. and Pomfret, G. (2003) Adventure Tourism: the New Frontier. Oxford: ButterworthHeinemann.

Tao, C.T., Eagles, P.F.J. \& Smith, S.L.J. (2010) Profiling Taiwanese Ecotourists Using a Self-definition Approach Profiling Taiwanese Ecotourists Using a Selfdefinition Approach. Journal of Sustainable Tourism 12(2), 149-168.

Tomljenović, R. and Marušić, Z. (2006) TOMAS Nacionalni parkovi i parkovi prirode 2006. In: S. Čorak and Z. Marušić eds. 2009. TOMAS trendovi - Stavovi i potrošnja turista u Hrvatskoj 1987-2008. Zagreb, Institut za turizam, pp.127-144
UNWTO (2007) Handbook on tourism market segmentation - Maximizing Marketing Effectiveness - A Report of the Market Intelligence Group of the European Travel Commission. Brussels: World Tourism Organisation and the European Travel Commission.

Walker, J.R. and Walker, J.T. (2011) Tourism, concepts and practices. New Jersey: Pearson Prentice Hall.

Walle, A.H. (1997) Pursuing risk or insight. Annals of Tourism Research 24 (2), 265282.

Weaver, D. (2001a) Ecotourism. Milton: John Wiley \& Sons, Ltd.

Weaver, D. (2001b) Ecotourism in the context of other tourism types. In: D. Weaver, ed. (2001). The encyclopedia of ecotourism. Wallingford: CAB International, pp.73-78

Weaver, D., Faulkner, B, and Lawton, L. (1999) Nature-based Tourism in Australia and Beyond: a Preliminary Investigation (CRC for Sustainable Tourism Research Report).Gold Coast, Queensland.

Weaver, D.B. and Lawton, L.J. (2002) Overnight Ecotourist Market Segmentation in the Gold Coast Hinterland of Australia. Journal of Travel Research 40(3), 270-280.

Weber, K. (2001) Outdoor adventure tourism. A Review of Research Approaches. Annals of Tourism Research 28(2), 360-377.

Wedel, M. and Kamakura, W.A. (2000) Market Segmentation - Conceptual and Methodological Foundations. 2nd ed. Boston: Kluwer Academic Publishers.

Wight, P. (1993) Sustainable Tourism: Balancing economic environmental and social goals within an ethical framework. Journal of Tourism Studies 4(2), 54-66.

Wight, P.A. (1996) North American Ecotourists: Market Profile and Trip Characteristics. Journal of Travel Research 34(2), pp.2-10.

Williams, P.W., Singh, T.V. and Schlüter, R. (2001) Mountain Ecotourism: Creating a Sustainable Future. In: D. Weaver, ed. (2001). The Encyclopedia of ecotourism. Wallingford: $C A B$ International, pp. 205218.

Zins, A. (1999) Destination Portfolios Using a European Vacation Style Typology. Journal of Travel and Tourism Marketing 8(1), 1-23. 